\title{
PERANAN FEAR OF MISSING OUT TERHADAP PROBLEMATIC SOCIAL MEDIA USE
}

\author{
Keyda Sara Risdyanti ${ }^{1}$, Andi Tenri Faradiba ${ }^{2}$ dan Aisyah Syihab ${ }^{3}$ \\ ${ }^{1}$ Fakultas Psikologi, Universitas Pancasila \\ Email: keydasararisdyanti@hotmail.com \\ ${ }^{2}$ Fakultas Psikologi, Universitas Pancasila \\ Email: atenri.frd@gmail.com \\ ${ }^{3}$ Fakultas Psikologi, Universitas Pancasila \\ Email: aisyah.syihab@gmail.com
}

\begin{abstract}
ABSTRAK
Sampel dalam penelitian ini berjumlah 254 remaja dalam rentang usia 12-22 tahun, dengan metode pengambilan Media sosial menjadi alat komunikasi sehari-hari bagi remaja masa kini. Kemudahan mengakses media sosial membentuk remaja memiliki keterikatan dengan akun media sosialnya. Perilaku ini memunculkan adanya dampak negatif bagi remaja, baik itu bagi dirinya sendiri maupun diluar dirinya, seperti merusak hubungan sosial dengan orang lain maupun mengganggu pendidikan remaja secara tidak langsung. Hanya saja, pemicu penggunaan media sosial yang tidak sehat ini, diakibatkan karena adanya kekhawatiran memiliki hubungan yang terputus dengan orang-orang disekitarnya. Maka dari itu, penelitian ini bertujuan untuk melihat seberapa besar peranan yang dimiliki oleh fear of missing out (FOMO) terhadap problematic social media use (PSMU). sampel berbasis internet melalui volunteer (opt in) panel. Fear of Missing Out scale sebagai alat pengukuran untuk FOMO, sedangkan Social Media Use Questionnaire digunakan untuk mengukur PSMU. Hasil penelitian memiliki signifikansi secara positif $(0,00>0,05)$, yang artinya semakin tinggi seseorang dalam memiliki perasaan takut, cemas, gelisah maupun khawatir bila tidak ikut terlibat dalam kegiatan sosial bersama orang disekitarnya, ia akan cenderung semakin memiliki keterikatan dengan media sosialnya hingga menimbulkan konsekuensi negatif bagi dirinya. Hasil juga menunjukan adanya sejumlah peranan yang diberikan oleh fear of missing out kepada problematic social media use sebesar $35,8 \%$, sedangkan sisanya dipengaruhi oleh faktor lain.
\end{abstract}

Kata kunci: fear of missing out, problematic social media use, remaja

\begin{abstract}
Social media has become the regular communication tool for today's youth. Ease of access media forms attachment of adolescents to their social media accounts. This behavior gives rise to negative impacts for adolescents, both for themselves and their surroundings, such as damaging social relationships with others and indirectly disrupting their education. Unhealthy use of social media is caused by fears of ruining relationships with people around them. Therefore, this study aims to see the extent to which the role of the fear of missing out (FOMO) affects problematic social media use (PSMU). The sample in this study amounted to 254 adolescents between 12-22 years age range, with internet-based sampling methods through volunteer (opt in) panels. The Fear of Missing Out scale is a measurement tool for FOMO, while the Social Media Use Questionnaire was used to measure PSMU. The result of the study indicated positive significance (0.00>0.05), which means that the more a person is having feelings of fear, anxiety, or worry when not involved in social activities with people around them, they tend to have more attachment to the media social which in turn, causes negative consequences for them. The result also showed a number of influence by the fear of missing out to the problematic social media use as much as 35.8\%, while the rest were influenced by other factors.
\end{abstract}

Keyword: fear of missing out, problematic social media use, adolescents 


\section{PENDAHULUAN}

\section{Latar Belakang}

Media sosial memiliki peran penting bagi remaja untuk tetap berhubungan dengan keluarga maupun teman-temannya. Erikson dalam Rathus (2007) mengungkapkan bahwa masa remaja merupakan tahap perkembangan yang menunjukkan kemampuan koneksi dan peran sosialnya, serta membentuk siapa dirinya. Kemampuan menjalin suatu koneksi tersebut digambarkan oleh Hawk (2018) yang menekankan bahwa usia remaja merupakan pengguna media sosial terbanyak dengan kisaran $70 \%$ usia muda, yang juga terdukung kemudahan akses melalui ponsel cerdas, komputer dan peralatan teknologi canggih lainnya. Hanya saja, Galagan, Gemmill \& Peterson dalam Alt (2017) menyatakan bahwa teknologi, khususnya media sosial, berperan sebagai pengalih perhatian karena memberikan berbagai fitur kesenangan di dalamnya.

Bila dilihat gambaran dalam lima hingga sepuluh tahun terakhir (sekitar tahun 2008-2018), pendidikan saat ini mulai memberlakukan sistem pembelajaran dengan teknologi berbasis internet, seperti dihadirkannya fitur-fitur edukasi yang dapat diakses melalui telepon cerdas. Salah satu hasil penelitian yang melibatkan kelompok siswa dengan proses belajar melalui bantuan alat digital, siswa lebih sering membuka konten diluar dari bahasan pembelajaran (Juncoa \& Cotten, 2012), salah satunya adalah mencuri waktu untuk membuka media sosial. kegiatan ini menunjukkan bahwa remaja sulit melepaskan diri dari telepon cerdasnya, ditambah lagi dengan adanya fitur-fitur hiburan dalam bentuk media sosial yang mudah proses pengaksesannya. Semakin terikatnya individu dengan media sosial, semakin sulitnya ia terlepas dari hal itu. Dalam bidang psikologi, hal ini dapat dikenal dengan istilah problematic social media use.

\section{Problematic Social Media Use}

Bányai dkk. (2017) mengartikan problematic social media use sebagai perubahan suasana hati dari rasa senang menggunakan media sosial menjadi perasaan negatif ketika tidak dapat mengakses media sosial, hingga menimbulkan konsekuensi negatif dalam kehidupan nyata dari hasil penggunaan media sosial. Problematic social media use merupakan suatu dorongan dari motivasi yang kuat untuk menggunakan media sosial, di mana diperlukan pengorbanan dalam waktu yang banyak serta usaha untuk dapat beraktivitas di media sosial walaupun mengganggu aktivitas sosial, pendidikan, pekerjaan, hubungan interpersonal, serta kesehatan dan kesejahteraan psikologisnya (Andreassen \& Pallesen, dalam Kircaburun, Jonason, \& Griffiths, 2018).

Hasil studi dari Kircaburun dkk. (2018) mengungkapkan bahwa karakter kepribadian dari problematic social media use digambarkan sebagai individu yang mengalami kesulitan dalam membangun hubungan sosialnya di dalam kehidupan nyata. Sama hal-nya bagi individu yang memiliki ketidakmampuan dalam memenuhi kebutuhan dasar manusia, seperti kebutuhan untuk mendapatkan dukungan sosial, kebutuhan untuk dapat terhubung dengan orang lain. Pada akhirnya, bentuk dari kekurangan stimulasi sosial tersebut membuat dirinya cenderung terikat dengan segala aktivitas dalam media sosial. Adanya penelitian yang menjelaskan salah satu faktor yang membuat seseorang mengalami problematic social media use, yaitu karena adanya rasa takut untuk tertinggal atau kehilangan informasi seperti apa saja yang dilakukan teman sebayanya, yang terdapat dalam media sosial (Alt, 2017). Kondisi ini dikenal dalam istilah psikologi dengan sebutan fear of missing out.

\section{Fear of Missing Out}

Fear of missing out merupakan rasa takut yang muncul dalam diri individu, bila orang lain bersenang-senang tanpa kehadirannya (Przybylski, Murayama, DeHaan, \& Gladwell, 2013). 
Gagasan tersebut menyebabkan fear of Missing Out dapat diibaratkan sebagai faktor pendorong dari keterikatan seseorang dengan telepon cerdasnya maupun media sosialnya (Buglass, Binder, Betts, \& Underwood, 2017). Abel, Buff dan Burr (2016) mendeskripiskan Fear of missing out sebagai dorongan yang kuat untuk berada di dua tempat atau lebih dalam satu waktu, disadari dari rasa ketakutan akan kehilangan sesuatu, sehingga media sosial sebagai wadah yang dapat ditempatkan sebagai suatu sumber kebahagiaan seseorang, khususnya dalam hal ikut merasakan setiap momen yang dialami oleh orang lain dari hasil mendapatkan informasi tersebut. Fear of missing out dikarakteristikkan sebagai keinginan untuk secara berkelanjutan tetap berhubungan dengan apa yang orang lain lakukan, khususnya dengan berhubungan melalui teknologi media sosial, yang mana memberikan kesempatan untuk melihat aktivitas yang dilakukan setiap orang (Przybylski dkk., 2013).Tidak heran bila banyaknya usia muda yang mengetahui keadaan rekan atau teman sebayanya, hanya dengan melihat media sosial satu sama lain sebagai rasa takut kehilangan informasi.

Fear of missing out didasari oleh teori self-determination dalam Deci dan Ryan (1985) yang mengungkapkan bahwa regulasi diri dan kesehatan psikologis dapat berjalan efektif ketika individu telah memenuhi tiga kebutuhan psikologis dasar, yaitu kompetensi (competence), otonom (autonomy), dan keterikatan (relatedness).

\section{Rumusan Masalah}

Berdasarkan beberapa penelitian sebelumnya dan teori yang menyatakan bahwa problematic social media use berhubungan dengan fear of missing out, penelitian ini dibuat untuk mencari tahu seberapa besar kontribusi yang terdapat pada fear of missing out terhadap problematic social media use pada usia remaja. Remaja yang berperan sebagai pengguna media sosial terbesar, serta merupakan tahapan perkembangan di mana terjadinya banyak perubahan baik secara emosi, tubuh, minat dan pola perilaku. Peneliti merasa tahapan usia remaja menjadi sasaran yang tepat untuk melihat gambaran dan peranan fear of missing out pada problematic social media use. Di sisi lain, kondisi dimana usia 12 tahun telah dijadikan usia minimal untuk mengakses media sosial, membuat peneliti akan membagi rentang usia remaja secara luas dari 12 hingga 22 tahun, yang mana akan dibagi ke dalam dua tahapan usia remaja yaitu remaja awal dan remaja akhir.

\section{METODE PENELITIAN \\ Karakteristik partisipan}

Karakteristik partisipan dalam penelitian ini adalah remaja dengan rentang usia 12-22 tahun $(M=18.65, S D=2.818)$, di mana jumlah partisipan 54 remaja laki-laki dan 200 remaja perempuan, dengan total 254 partisipan. Teknik pengambilan sampel menggunakan teknik volunteer (opt in) panel, yang merupakan metode pengambilan sampel berbasis internet berdasarkan kesukarelaan partispan untuk mengisi kuesioner hasil dari persebaran di situs jejaring sosial. Partisipan dalam penelitian ini berasal dari wilayah Jabodetabek.

\footnotetext{
Alat ukur

Dalam penelitian ini, peneliti mengadaptasi alat ukur Fear of Missing Out scale (FOMOs) dari Wegmann, Oberst, Stodt dan Brand (2017) yang memiliki sejumlah 12 item dengan pengukuran lima skala likert dari "Sangat Tidak Sesuai" hingga "Sangat Sesuai". FOMOs mengandung dua komponen yaitu, trait-fomo dan state-fomo. Trait-fomo diartikan sebagai sifat bawaan dari proses kesadaran diri dalam berinternet, yang menghasilkan perasaan-perasaan tertentu ketika tertinggal informasi maupun komunikasi dengan orang lain. Contoh item dari komponen ini yaitu "Ketika saya tidak menghadiri kegiatan berkumpul yang telah direncanakan, hal itu mengganggu saya". Sebaliknya, state-fomo lebih kepada kecenderungan munculnya perlakuan atau perasaan yang
} 
umumnya mungkin terjadi pada orang lain dan bersifat sementara. Contoh item dari komponen ini adalah "Saya terus menerus online karena tidak ingin melewatkan hal apapun". Nilai reliabilitas yang dimiliki dalam alat ukur ini ialah 0,87 untuk keseluruhan 12 item yang dinyatakan valid.

Sedangkan untuk pengukuran PSMU, peneliti mengadaptasi alat ukur Social Media Use Questionnaire (SMUQ) dari Xanidis dan Brignell (2016) yang memiliki sejumlah 9 item dengan pengukuran lima skala likert dari "Tidak Pernah" hingga "Selalu". SMUQ mengandung dua komponen yaitu withdrawal dan compulsion. Withdrawal dapat diartikan sebagai kecenderungan timbulnya perilaku-perilaku yang berunsur menarik diri dari lingkungan sekitarnya, dengan berpusat pada sosial media. Contoh item dari komponen ini yaitu "Saya menggunakan media sosial ketika saya sedang bersama teman-teman". Sebaliknya, compulsion merupakan kecenderungan timbulnya perilaku-perilaku yang berunsur berlebihan dalam melakukan aktivitas di media sosial. Contoh item dari komponen ini yaitu "Saya lupa waktu ketika menggunakan media sosial". Nilai reliabilitas yang dimiliki dalam alat ukur ini adalah 0,82 berdasarkan 8 item yang dinyatakan valid dan dipertahankan.

\section{Prosedur}

Partisipan dengan jumlah 254 orang diarahkan untuk mengisi kuesioner perilaku online yang terdiri dengan lima skala likert dari total 21 item kuesioner. Mereka diminta untuk memilih jawaban yang sesuai dengan diri mereka sendiri, dengan tambahan informasi bahwa tidak ada jawaban yang benar maupun salah, serta segala informasi yang tersimpan hanya untuk kepentingan penelitian. Analisis uji korelasi yang dilakukan menggunakan SPSS 16 for windows.

\section{HASIL DAN PEMBAHASAN}

Dari hasil uji korelasi pada fear of missing out dengan problematic social media use mengunjukkan terdapat hubungan yang dimiliki kedua variabel dengan signifikansi yang positif $(0,00>0,05)$. Hal ini menjelaskan bahwa seseorang yang memiliki rasa ketakutan atau kekhawatiran untuk tertinggal dari suatu informasi yang berharga dari orang sekitarnya, cenderung memiliki perilaku penggunaan media sosial secara berlebihan, yang mana perilaku berlebihan disini merujuk pada berbagai dampak negatif pada diri penggunanya.

Tabel 1. Hasil korelasi fear of missing out dengan problematic social media use

\begin{tabular}{ccc}
\hline$r$ & $r^{2}$ & $\mathrm{p}$ \\
\hline 0.599 & 0.358 & .000 \\
\hline
\end{tabular}

Hasil penelitian ini mendukung penelitian sebelumnya yang dilakukan Franchina, Vanden Abeele, van Rooij, Lo Coco \& De Marez (2018) yang menyatakan bahwa fear of missing out menjadi salah satu faktor yang membentuk seseorang dapat mengalami problematic social media use. Seseorang yang mengalami fear of missing out akan cenderung mengalihkan rasa cemasnya dengan memantau kehidupan orang lain melalui media sosialnya. Hanya saja, bila perilaku tersebut dilakukan secara terus-menerus, hal ini juga akan cenderung memunculkan perasaan semakin tertinggal dari setiap kejadian-kejadian berharga yang telah dilalui oleh orang lain berdasarkan akun media sosial yang dilihat (Buglass dkk, 2017; Elhai, Dvorak, Levine \& Hall, 2018; Fuster, Chamarro \& Oberst, 2017; Oberst dkk, 2017; Scott \& Woods, 2018; Wegmann dkk, 2017). Kondisi seperti ini justru juga bisa memberikan sumber baru bagi munculnya 
perilaku fear of missing out. Sehingga dapat dikatakan bahwa fear of missing out dan problematic social media use masih memiliki hubungan timbal balik satu sama lain.

Perhitungan korelasi dari kedua variabel menunjukkan hasil R Square senilai 0,358 yang dapat disimpulkan bahwa peranan yang diberikan oleh fear of missing out kepada problematic social media use sejumlah $35,8 \%$, sedangkan $64,2 \%$ dipengaruhi oleh faktor lain. Faktor-faktor tersebut ialah seperti tipe kelekatan hubungan, subjective well-being, self-esteem, tipe kepribadian, kecemasan serta depresi (Andreassen dkk, 2016; Barker, 2009; Ehrenberg, Juckes, White \& Walsh, 2008; Elhai dkk, 2016; Kim, Seo \& David, 2015; Kircaburun, Jonason \& Griffiths, 2018; Odacı \& Çıkrıkçı, 2014).

\section{KESIMPULAN DAN SARAN}

Dari hasil dan analisa yang ditemukan dapat disimpulkan bahwa perilaku problematic social media use dan fear of missing out memiliki hubungan signifikansi yang positif serta masih memberikan hubungan timbal balik satu sama lainnya. Bagi penelitian selanjutnya, ada baiknya hal ini perlu dianalisa kembali secara sistem longitudinal, untuk melihat gambaran perilaku problematic social media use secara konstan dan dapat menjadi penelitian lanjutan khususnya pada topik pembahasan terkait problematic social media use ini. Hal kedua yang dapat dipertimbangkan selanjutnya ialah, karakteristik partisipan yang lebih beragam. Salah satunya seperti melihat bagaimana perbandingan sikap penggunaan media sosial pada beragam media sosial. Hal lain yang juga bisa dipertimbangkan adalah keragaman karakteristik usia. Hasil penelitian ini menunjukkan tidak adanya perbedaan yang signifikan pada remaja awal maupun remaja akhir. Ada kemungkinan rentang usia yang dibandingkan kurang bervariasi, dan juga pola karakteristik yang cenderung sama pada kategori usia remaja membuat hal ini tidak dapat dibandingkan secara lebih dalam. Ada kemungkinan dengan banyaknya variasi kategori usia pengguna media sosial, dapat menggambarkan adanya perbedaan problematika yang dimiliki pada masing-masing usia.

\section{Ucapan Terima Kasih (Acknowledgement)}

Peneliti mengucapkan terima kasih kepada pihak-pihak yang telah membantu dalam penyusunan artikel ini serta kepada seluruh partisipan yang telah bersedia ikut andil di dalam penelitian ini.

\section{REFERENSI}

Abel, J. P., Buff, C. L. and Burr, S. A. (2016). Social media and the fear of missing out: scale development and assessment. Journal of Business \& Economics Research, 14(1), 33.

Andreassen, C. S., Billieux, J., Griffiths, M. D., Kuss, D. J., Demetrovics, Z. and Mazzoni, E. (2016). The relationship between addictive use of social media and video games and symptoms of psychiatric disorders: A large-scale cross-sectional study. Psychology of Addictive Behaviors, 30(2): 252-62.

Bányai, F., Zsila, Á., Király, O., Maraz, A., Elekes, Z., Griffiths, M. D., and Demetrovics, Z. (2017). Problematic social media use: Results from a large-scale nationally representative adolescent sample. PLoS One, 12(1): e0169839.

Barker, V. (2009). Older adolescents' motivations for social network site use: The influence of gender, group identity, and collective self-esteem. Cyberpsychology \& behavior, 12(2), 209-213. 
Buglass, S. L., Binder, J. F., Betts, L. R., and Underwood, J. D. (2017). Motivators of online vulnerability: The impact of social network sites use and FOMO. Computer Human Behavior, 66, 248-255.

Deci, E. L., and Ryan, R. M. (1985). Intrinsic motivation and self-determination in human behavior. New York: Plenum .

Ehrenberg, A., Juckes, S., White, K. M., and Walsh, S. P. (2008). Personality and selfesteem as predictors of young people's technology use. Cyberpsychology \& Behavior, 11(6), 739 741

Elhai, J. D., Dvorak, R. D., Levine, J. C., and Hall, B. J. (2016). Problematic smartphone use: A conceptual overview and systematic review of relations with anxiety and depression psychopathology. Journal of affective disorders, 207, 251-259.

Franchina, V., Vanden Abeele, M., van Rooij, A., Lo Coco, G., and De Marez, L. (2018). Fear of Missing Out as a Predictor of Problematic Social Media Use and Phubbing Behavior among Flemish Adolescents. International journal of environmental research and public health, 15(10), 2319.

Fuster, H., Chamarro, A., and Oberst, U. (2017) Fear of missing out, online social networking and mobile phone addiction: A latent profile approach. Revista de Psicologia Ciències de l'Educació i de l'Esport, 35, 23-30.

Hawk, S. T., van den Eijnden, R. J., van Lissa, C. J., \& Bogt, T. F. (2019). Narcissistic adolescents' attention-seeking following social rejection: Links with social media disclosure, problematic social media use, and smartphone stress. Computers in Human Behavior, 92, 65-75.

Juncoa, R., and Cotten, S. R. (2012). No. A4U: The relationship between multitasking and academic performance. Computers \& Education, 59(2), 505-514

Kim, J., Seo, M., and David, P. (2015). Alleviating depression only to become problematic mobile phone users: Can face-to-face communication be the antidote? Computers in Human Behavior, 51, 440-447.

Kircaburun, K., Jonason, P. K., and Griffiths, M. D. (2018). The Dark Tetrad traits and problematic social media use: The mediating role of cyberbullying and cyberstalking. Personality and Individual Differences, 135, 264-269.

Kircaburun, K., Kokkinos, C. M., Demetrovics, Z., Király, O., Griffiths, M. D., and Çolak, T. S. (2018). Problematic online behaviors among adolescents and emerging adults: Associations between cyberbullying perpetration, problematic social media use and psychosocial factors. International Journal of Mental Health and Addiction, 1-18.

Oberst, U., Wegmann, E., Stodt, B., Brand, M., and Chamarro, A. (2017). Negative consequences from heavy social networking in adolescents: The mediating role of fear of missing out. Journal of Adolescence, 55, 51-60.

Odacı, H., and Çıkrıkçı, Ö. (2014). Problematic internet use in terms of gender, attachment styles and subjective well-being in university students. Computers in Human Behavior, 32, 6166.

Przybylski, A. K., Murayama, K., DeHaan, C. R., and Gladwell, V. (2013). Motivational, emotional, and behavioral correlates offear ofmissing out. Computers in Human Behavior, $29,1841-1848$.

Rathus, S. A. (2007). Childhood and adolescence: Voyages in development, fifth edition. USA: Wadsworth Cengage Learning.

Scott, H. and Woods, H. C. (2018). Fear of missing out and sleep: Cognitive behavioural factors in adolescents' nighttime social media use. J. Adolesc., 68, 61-65. 
Wegmann, E., Oberst, U., Stodt, B., and Brand, M. (2017). Addictive Behaviors Reports Onlinespecific fear of missing out and Internet-use expectancies contribute to symptoms of Internet-communication disorder. Addictive Behaviors Reports, 5, 33-42.

Xanidis, N. and Brignell, C. M. (2016). Computers in Human Behavior The association between the use of social network sites, sleep quality and cognitive function during the day. Computers in Human Behavior, 55, 121-126. 